Article

\title{
Liquid Propane Injection in Flash-Boiling Conditions
}

\author{
Lukasz Jan Kapusta ${ }^{1, *(\mathbb{D}}$, Jakub Bachanek ${ }^{1}{ }^{1}$, , Changzhao Jiang ${ }^{2}$, Jakub Piaszyk ${ }^{2}$, Hongming $\mathrm{Xu}^{2}$ \\ and Mirosław Lech Wyszyński ${ }^{2}$ \\ 1 Institute of Heat Engineering, Faculty of Power and Aeronautical Engineering, Warsaw University of \\ Technology, Nowowiejska 21/25, 00-665 Warsaw, Poland; jakub.bachanek@pw.edu.pl \\ 2 Department of Mechanical Engineering, School of Engineering, The University of Birmingham, \\ Birmingham B15 2TT, UK; cxj956@bham.ac.uk (C.J.); J.Piaszyk@bham.ac.uk (J.P.); H.M.Xu@bham.ac.uk (H.X.); \\ M.L.Wyszynski@bham.ac.uk (M.L.W.) \\ * Correspondence: lukasz.kapusta@pw.edu.pl
}

Citation: Kapusta, Ł.J.; Bachanek, J.; Jiang, C.; Piaszyk, J.; Xu, H.; Wyszyński, M.L. Liquid Propane Injection in Flash-Boiling Conditions. Energies 2021, 14, 6257. https://doi.org/

Academic Editor: Octavio Armas

Received: 18 August 2021

Accepted: 27 September 2021

Published: 1 October 2021

Publisher's Note: MDPI stays neutral with regard to jurisdictional claims in published maps and institutional affiliations.

Copyright: (C) 2021 by the authors. Licensee MDPI, Basel, Switzerland. This article is an open access article distributed under the terms and conditions of the Creative Commons Attribution (CC BY) license (https:/ / creativecommons.org/licenses/by/ $4.0 /)$.

\begin{abstract}
This study aimed to investigate the influence of flash-boiling conditions on liquid propane sprays formed by a multi-hole injector at various injection pressures. The focus was on spray structures, which were analysed qualitatively and quantitatively by means of spray-tip penetration and global spray angle. The effect of flash boiling was evaluated in terms of trends observed for subcooled conditions. Propane was injected by a commercial gasoline direct injector into a constant volume vessel filled with nitrogen at pressures from $0.1 \mathrm{MPa}$ up to $6 \mathrm{MPa}$. The temperature of the injected liquid was kept constant. The evolution of the spray penetration was observed by a high-speed camera with a Schlieren set-up. The obtained results provided information on the spray evolution in both regimes, above and below the saturation pressure of the propane. Based on the experimental results, an attempt to calibrate a simulation model has been made. The main advantage of the study is that the effects of injection pressure on the formation of propane sprays were investigated for both subcooled and flash-boiling conditions. Moreover, the impact of the changing viscosity and surface tension was limited, as the temperature of the injected liquid was kept at the same level. The results showed that despite very different spray behaviours in the subcooled and flash-boiling regimes, leading to different spray structures and a spray collapse for strong flash boiling, the influence of injection pressure on propane sprays in terms of spray-tip penetration and spray angle is very similar for both conditions, subcooled and flash boiling. As for the numerical model, there were no single model settings to simulate the flashing sprays properly. Moreover, the spray collapse was not represented very well, making the simulation set-up more suitable for less superheated sprays.
\end{abstract}

Keywords: flash boiling; spray; injection; propane; LPG; spray collapse; multi-hole injector

\section{Introduction}

In large-bore gas engines' development, two main trends may be observed. One is aimed at increasing engine efficiency and BMEP (brake mean effective pressure), and the other is focused on the utilisation of non-conventional gases. Increasing the BMEP is limited due to the fuel's propensity towards combustion knock. Replacing natural gas with alternative fuels can also be limited by knocking. While natural gas has a high methane number and assures knock-free operation, other gases like propane and butane are not as knock-resistant as methane. Although utilising fuels such as LPG (liquefied petroleum gas) is possible, engine output de-rating is required. The option to limit knock propensity in the case of liquified gases utilises the charge-cooling effect, by injecting the gas into the intake port in liquid form. In such an approach, the rapid vaporisation occurring due to pressure lower than the vapour pressure of propane or butane will consume much heat from the charge air flowing through the intake channels. This would also improve the volumetric efficiency [1]. On the other hand, the flash-boiling effect will lead to a drastic change in a spray's behaviour [2,3], which needs to be taken into account. 
Flash boiling has been considered as one of the methods to enhance droplet break-up, decrease the penetration of the spray and widen its angle. It has been broadly investigated in terms of gasoline direct injection. Nevertheless, it has been documented to strongly alter the spray's properties regardless of the fuel type [4]. After the liquid is exposed to an environment pressure lower than the substance's vapour pressure, the rapid formation of the vapour bubbles inside the droplets leads to their micro explosions and the formation of smaller droplets [5,6]. Moreover, these explosions are the source of additional momentum, which changes the axial-to-radial momentum ratio. As an effect, the global spray properties such as spray angle and spray-tip penetration are strongly modified as well. It has been reported that the spray-tip penetration and droplet size can be reduced, and the spray angle increased [3,7-9]. Araneo et al. [7] carried out a study on iso-octane sprays formed at $7 \mathrm{MPa}$ injection pressure. The results showed that increasing the temperature of the fuel from $293 \mathrm{~K}$ to $393 \mathrm{~K}$ led to a reduction of the mean diameter by about a half under $40 \mathrm{kPa}$ ambient pressure conditions. They concluded that a substantial widening of the spray angle at the nozzle exit was observed when the fuel temperature was above the fuel's boiling point at considered ambient conditions. According to the study of Vanderwege and Hochgreb [3], for the same liquid, a superheat degree of about $20 \mathrm{~K}$ is needed to detect noticeable changes in the spray structure. More recently, Wang et al. [10] studied the influence of injection pressure on iso-octane sprays formed under flash-boiling conditions by a single-hole injector. They reported that the higher injection pressure led to a narrower spray angle. They linked it with the impact of hydraulic force.

However, the observations made for single- and multi-hole injectors can be distinguished. The conditions, i.e., how strongly the fuel is superheated (in relation to the ambient pressure), also play a significant role in the effect of flash boiling on spray formation.

In strong flash-boiling conditions (fuel is highly superheated), the spray formation can be very different depending on the number of nozzles [11]. In the case of multi-hole injectors, the individual plumes may collapse towards the centre of the spray cloud and form a spray cloud with a decreased angle and increased spray penetration, which is considered as a "flare" flash-boiling regime [12]. Zeng et al. [12] reported that this regime was observed when the fuel saturation-to-ambient pressure ratio $R_{p}$ was above 3.33. They tested three different fuels (methanol, ethanol and $n$-hexane), and similar trends were observed. When the $R_{p}$ was in the lower range (1-3.33), the flash boiling had a similar effect on spray formation as for a single-hole injector-with the increasing $R_{p}$ the penetration was decreasing, and the spray plume width was increasing. For the $R_{p}$ lower than one, the spray was subcooled. A similar spray collapse was reported by Xu et al. [13]. They investigated the effect of flash boiling on gasoline, ethanol, methanol and $n$-hexane sprays formed at different injection pressures ( $3-15 \mathrm{MPa}$ ). They focused on the flash-boiling effects in terms of three spray-formation regimes: subcooled, transitional and flare flash-boiling. In the transitional regime, with the increase of the $R_{p}$, the smaller droplets were formed; while in the flare flash-boiling regime, the droplet size remained fairly constant regardless of the $R_{p}$. As for the injection pressure, they observed that the effect of flash boiling was stronger when it was lower. Lower injection pressure resulted in a faster reduction of the droplet size and led to its more substantial overall reduction. Although at some point the droplet size became constant regardless of the $R_{p}$, its further increase influenced the global spray parameters, and this was observed for different injection pressures. According to Yang et al. [14], a lower injection pressure led to a stronger formation of the vapour bubbles.

While most of the studies related to spray formation from multi-hole injectors were done for liquid fuels, the liquified gases have not been investigated so often. However, there are important studies performed for propane.

Lacey et al. [15] studied both propane and iso-octane sprays formed at injection pressure of $20 \mathrm{MPa}$ in flash-boiling conditions. Their study confirmed that the geometrical parameters of the injector are an important factor, which determines how the flash boiling influences the global parameters of the spray. They proposed a new criterion for the spray collapse which was based on both the thermodynamic parameters of the fuel and 
the ambience and the geometrical parameters of the injector. Later, Poursadegh et al. [16] investigated propane sprays formed in SIDI (spark ignition direct injection) engine-relevant conditions. They varied the injection pressure, ambient pressure, fuel temperature and ambient temperature. Due to the proximity of the critical point, they observed a wide variety of spray types, including conventional (subcooled), flash boiling, and, finally, gas-like injection with clear evidence of shock structures. As for the injection pressure, they reported that at flash-boiling conditions (fuel temperature $360 \mathrm{~K}$, ambient pressure $50 \mathrm{kPa}$ ), higher injection pressure led to a higher plume expansion. Zhang et al. [17] investigated propane sprays to compare their characteristics in trans-critical and flashboiling conditions. For trans-critical sprays, they observed clear shock structures when the temperature of the fuel was above $120^{\circ} \mathrm{C}$, and the injection pressure was above a specific limit. For a constant injection pressure $(12 \mathrm{MPa})$ and constant fuel temperature $\left(120^{\circ} \mathrm{C}\right)$, the penetration of the sprays injected into constant-temperature environments $\left(20^{\circ} \mathrm{C}\right)$ was shown to decrease with the ambient pressure. The injection pressure was varied only for trans-critical conditions (fuel temperature 100 and $120^{\circ} \mathrm{C}$, ambient pressure $0.1 \mathrm{MPa}$ and ambient temperature $20^{\circ} \mathrm{C}$ ).

Kim et al. [18] studied propane sprays to provide experimental data for the purpose of numerical model development. They evaluated the effect of injection pressure on the spray-tip penetration at three different ambient pressures. Regardless of the ambient pressure, the effect of the injection pressure was similar. The higher the injection pressure, the higher the penetration.

One may conclude that the works on propane sprays in which different injection pressures were investigated do not directly compare the pressure effect under subcooled and flash-boiling conditions. The results reported in different studies cannot be compared as the behaviour of the spray does depend on the geometrical configuration of the injector. The same thermodynamic conditions of the fuel and the ambience are not sufficient to conclude on the interaction of the injection pressure and the flash boiling, and their combined effect on propane sprays formed by multi-hole injectors. The other important aspect is that most of the studies on flash-boiling sprays formed by multi-hole injectors focused on the penetration of the whole spray cloud. However, under certain conditions, individual plumes start to interact. It is not clear how the propagation of the single plume in a flashing propane spray formed by a multi-hole injector will depend on the thermodynamic conditions (including different spray formation regimes, i.e., subcooled and flash boiling).

This study is aimed at the analysis of the flash-boiling effect on the structures of liquid propane sprays formed at different injection pressures in terms of trends observed for subcooled conditions. Our goal was to reduce the injection pressure strongly compared to typical SIDI (spark ignition direct injection) engine-relevant conditions. In order to limit the impact of changing viscosity and surface tension, the temperature of the injected liquid was kept at the same level. As liquid propane in the ambient environment is superheated, a wide range of ambient pressures was considered to reach subcooled states. The spray structures were analysed in terms of spray-tip penetration (in the direction of the single plume) and the spray angle (angle at the visualisation plane). The spray-tip penetration was measured along the axis of the single plume in order to assess how the propagation of the single plume is affected by the surrounding plumes in flash-boiling conditions, including the strong collapse of the spray, depending on the injection pressure.

Although this work's primary motivation was related to the application of liquid propane injection into the intake manifold, this study shall be treated as a preliminary investigation aimed at understanding the spray behaviour in highly flashing conditions in relation to the subcooled cases, especially in terms of changing injection pressure.

Based on the experimental results, the preliminary calibration of the Lagrangian flashboiling model was performed for the purpose of further engine simulations. The literature reveals some numerical studies which focused on a flashing propane spray. However, in most studies, Euler-Euler multiphase modelling is used to gather detailed information on flashing jet expansion near the injector's nozzle. Rapid evaporation of fuel leads to large 
temperature and density gradients $[19,20]$. This may cause shock waves, which can be the reason for the spray collapse mechanism [4,21]. Along with adaptive mesh refinement, the Euler-Euler approach with a volume-of-fluid model allows the prediction of the occurrence of shock waves in high-superheat cases and in liquified gaseous fuel simulations [21]. Gärtner et al. [20] investigated a multiphase propane spray using OpenFOAM. They reported that the results from the simulations were in line with the assumption that the spray collapses due to the interaction of the shock waves. However, the fully multiphase simulations require high computational power. In engine applications, the discrete droplet model is widely used due to its much lower computational cost. Kim et al. [18] used a modified gas-jet model in Lagrangian propane spray simulations to improve the prediction of the spray behaviour. However, only fully flare-flashing sprays were validated and analysed. In this study, the Lagrangian model is used as there is the intention to carry out further engine simulations.

The main advantage of this study is that the effects of injection pressure on the formation of propane sprays were investigated for both subcooled and flash-boiling conditions. Moreover, the impact of changing viscosity and surface tension was limited as the temperature of the injected liquid was kept constant. Additionally, the results are used to calibrate a numerical model intended for future engine simulations.

\section{Materials and Methods}

The study included both experiments as well as numerical modelling. Thus, the materials and methods related to each of these parts are presented in the following separate subsections.

\subsection{Experimental Study}

The experiments were conducted in a constant volume vessel (Figure 1a) equipped with two oppositely located quartz windows providing optical access for the Schlieren visualisation. The interior of the vessel was cylindrical with a diameter of $85.2 \mathrm{~mm}$ and a height of $120 \mathrm{~mm}$. The z set-up of the Schlieren imaging was used in the study (Figure 1b). The Schlieren set-up was based on $100-\mathrm{mm}$ parabolic mirrors, but due to the limited optical access, only the oval area $(22 \times 35 \mathrm{~mm})$ was illuminated.

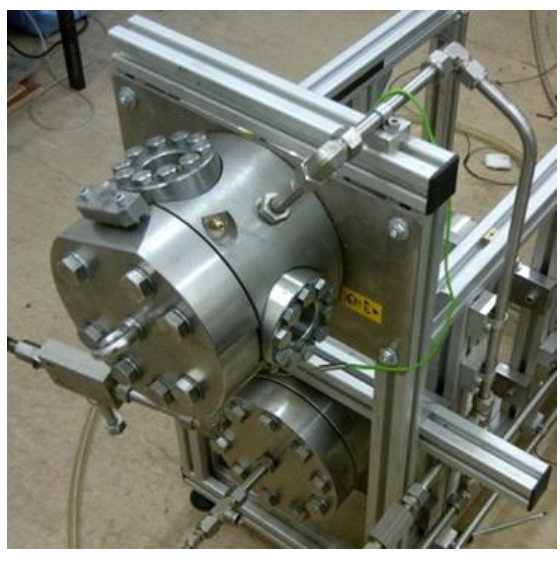

(a)

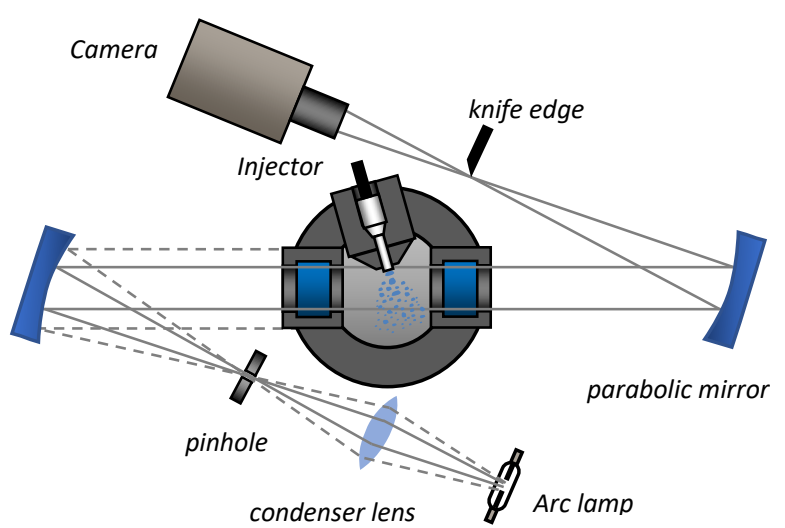

(b)

Figure 1. Experimental set-up: (a) constant volume vessel; (b) schematic diagram of the Schlieren set-up used in the experiments.

Although our primary motivation was related to the application of a liquid propane injection into the intake manifold, we have used a typical SIDI injector-a commercial gasoline direct injector Bosch Hdev 5.1 (8W93-9F593-AC). It was used due to two reasons. Firstly, regular port-fuel injectors are not designed to work under sufficiently high pressures to inject liquid propane without extensive cooling. Secondly, reference cases 
for the subcooled conditions were needed to conclude on the effect of flash boiling. In order to limit the impact of changing viscosity and surface tension, the temperature of the injected liquid was kept constant. Thus, the subcooled conditions needed to be reached by increasing the ambient pressure. Higher ambient pressures, in turn, required increased injection pressures (typical for SIDI injectors).

The injector was mounted into the vessel, so the axis of the spray plume coming out from one of the six nozzles was perpendicular to the light beam passing through the vessel. This allowed us to directly measure the penetration along the axis of the single plume. The comparison of the spray pattern model view with the image obtained experimentally is shown in Figure 2.

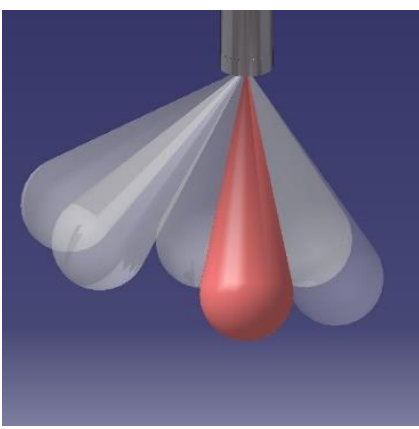

(a)

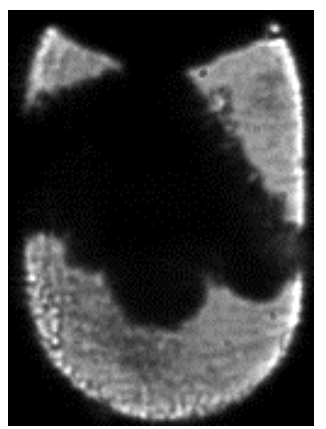

(b)

Figure 2. View of the spray pattern: (a) model, a plume with the axis perpendicular to the line of sight was marked red; (b) experiment image.

The spray formation process was recorded by a high-speed camera (Phantom v710). The image resolution was $128 \times 256$ pixels, and the images were captured with a frequency of $100,000 \mathrm{fps}$. The spatial resolution was $0.188 \mathrm{~mm} /$ pix.

The injector control system and the camera were initiated by the same trigger signal from an additional pulse generator. The trigger in the high-speed camera was set at the start of the recording sequence.

The measurement points were selected in such a way as to investigate the effect of injection pressure $p_{i n j}$ at the ambient pressure $p_{a m b}$ below and above the vapour pressure of propane $\left(p_{a m b}=0.1,2\right.$ and $6 \mathrm{MPa}$ abs). Although this study's primary motivation was related to applying the liquid propane injection into the intake manifold, the lowest considered injection pressure was $2 \mathrm{MPa}$. This value was regarded as a minimum pressure to keep the propane in liquid form in practical systems (e.g., avoid cavitation in a fuel system in the case of temperature increase). Additionally, the effect of the changing ambient pressure in the whole considered range (0.1-6 MPa) was investigated for the maximum studied injection pressure (14 MPa). The accuracy of the pressure measurement was $\pm 0.002 \mathrm{MPa}$ for the pressures $0.1-2 \mathrm{MPa}$ and $\pm 0.025 \mathrm{MPa}$ for the pressures above $2 \mathrm{MPa}$. The temperatures of the ambience and the injected liquid were kept at a very similar level $(294 \pm 1 K)$. The considered conditions in the chamber and in the injector, along with the vapour pressure curve for propane, are shown in Figure 3.

The composition of the gas in the chamber remained the same in all investigated cases, and for this purpose, pure nitrogen was used. The injection duration was $2 \mathrm{~ms}$, so at the highest considered ambient pressure, the spray tip could reach the visualisation limit. During the experiments, slight deviations from the target values were observed. The temperatures were monitored by two thermocouples, and the measured values were used later on to calculate the fuel saturation-to-ambient pressure ratio, which is reported in the next section. 


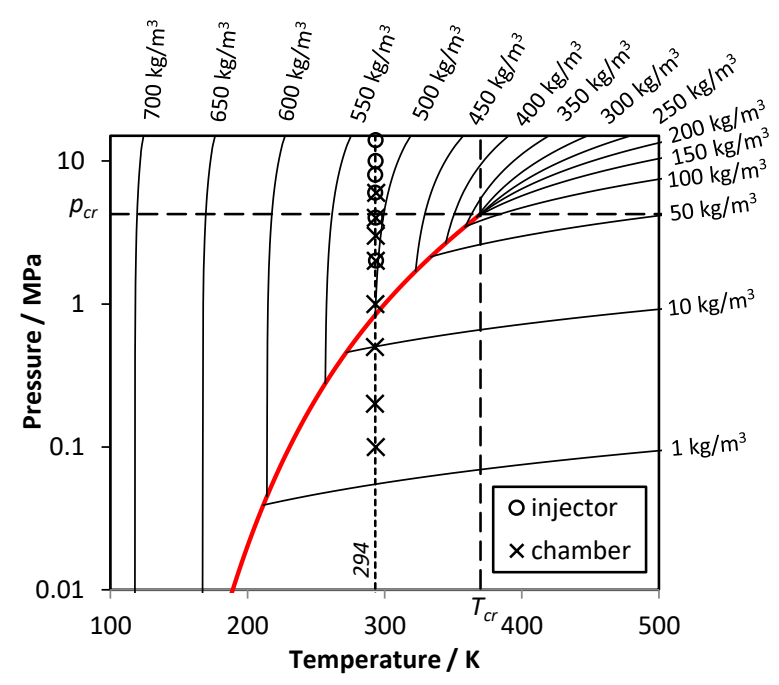

Figure 3. Propane parameters in the injector and chamber conditions at the start of injection: propane vapour pressure curve (thick red line) and propane isochores (thin black lines); data from [22].

The images were processed using LaVision DaVis software (version 8.4). The spray-tip penetration was determined based on the location of $99 \%$ of the pixels (above the intensity threshold of 45 in the 8-bit images) from the injector tip. The spray-tip penetration was measured along the axis of the selected single plume in order to assess how the propagation of the single plume is affected by the surrounding plumes. The measurement error was $\pm 0.188 \mathrm{~mm}$ and was a direct effect of low spatial resolution. The spray angle, in turn, was determined based on the side profiles of the spray (separated from the background using the same intensity threshold of 45), assuming that the sides of the angle must go through the nozzles' edges. Figure 4 shows the raw Schlieren images captured $0.2 \mathrm{~ms}$ ASOI (after the start of injection) for the subcooled and intensive flash-boiling conditions with marked spray-tip penetration and spray angle.

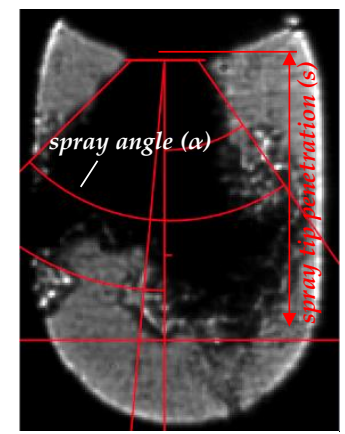

(a)

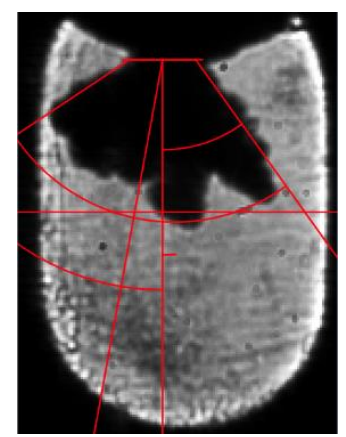

(b)

Figure 4. The raw Schlieren images with marked spray angle and spray-tip penetration captured 0.2 ms ASOI: (a) flash-boiling conditions $\left(R_{p}=8.36\right)$; (b) subcooled conditions $\left(R_{p}=8.36\right)$.

\subsection{Numerical Modelling}

To describe the behaviour of the dispersed spray's droplets, the discrete droplet model (DDM) was used. Particles of similar parameters are grouped into so-called parcels and tracked in the computational cells. Many propane studies have been focused on the fully Eulerian approach, due to the gaseous state of propane under normal conditions. The under-expanded flashing jets may lead to the occurrence of shock waves near the exit of the injector [23]. Therefore, full-multiphase models are usually preferred. In this paper, the macro-scale spray structure is analysed for the purpose of further engine simulations. 
Thus, a DDM spray representation is selected. The DDM approach is characterised by a much lower computational time and mesh requirements.

The flash-boiling model contains two sub-models-the enhanced evaporation and flashing atomisation due to gas nucleation and bubble growth. The evaporation model follows the approach proposed by Zuo et al. [24], which is based on the correlation of Adachi et al [25] (Equation (2)). To calculate the total evaporation rate $\dot{m}_{e v}$, the flashing evaporation rate $\dot{m}_{f}$ is added to the standard evaporation rate $\dot{m}_{h t}$ (Equation (1)). The standard evaporation rate is additionally affected by the flash boiling (Equation (3)).

$$
\begin{gathered}
\dot{m}_{e v}=\dot{m}_{f}+\dot{m}_{h t} \\
\dot{m}_{f}=\frac{\alpha_{s h}\left(T_{d}-T_{b}\right) A_{d}}{L\left(T_{b}\right)} \\
\dot{m}_{h t}=2 \pi \frac{k}{c_{p}} r_{0} \frac{N u}{1+\frac{\dot{m}_{f}}{\dot{m}_{h t}}} \ln \left(1+\left(1+\frac{\dot{m}_{f}}{\dot{m}_{h t}}\right) \frac{h_{\infty}-h_{b}}{L\left(T_{b}\right)}\right)
\end{gathered}
$$

where $\alpha_{\text {sh }}$ is the overall heat transfer coefficient from the interior of the droplet to its surface; $T_{d}$ is the droplet temperature; $T_{b}$ is the fuel's boiling temperature; $A_{d}$ is the droplet surface; $L\left(T_{b}\right)$ is the latent heat of vaporisation at the boiling temperature; $k$, is the gaseous thermal conductivity; $c_{p}$ is the specific heat; $N u$ is the Nusselt number; $h_{\infty}-h_{b}$ is the difference between the gas enthalpy in the mixture and at the droplet's surface, respectively. When the conditions for the flash boiling end, the Abramzon/Sirignano approach [26] is used for further evaporation calculations. The coefficient $\alpha_{s h}$ depends on the difference between the droplet and the boiling temperature $\Delta T$ :

$$
\begin{array}{lr}
\alpha_{\text {sh }}=760 \cdot \Delta T^{0.26} & 0<\Delta T \leq 5 \\
\alpha_{\text {sh }}=27 \cdot \Delta T^{2.33} \quad 5<\Delta T \leq 25 \\
\alpha_{\text {sh }}=13,800 \cdot \Delta T^{0.39} \quad 25<\Delta T
\end{array}
$$

The temperature change of the flashing droplet is calculated as follows:

$$
\frac{d T_{d}}{d t}=\frac{A_{d} \alpha_{s h}\left(T_{d}-T_{b}\right)}{\rho c_{v} V}
$$

where $\rho$ is the fuel density; $c_{v}$ is the constant volume heat capacity of the fuel; and $V$ is the droplet volume.

Flash boiling does not only enhance evaporation on the liquid surface. Additionally, the vapour bubbles are generated inside the droplets. The bubble number density defines the amount of vapour nucleation. One of the common approaches to calculating the value of the bubble number density $N$ is to use the formula proposed by Senda et al. [27]:

$$
N=f_{2} \cdot 5.757 \cdot 10^{12} \cdot \exp \left(\frac{-5.279}{\Delta T}\right)
$$

where $f_{2}$ is the correction factor. In this study, this factor was set individually for each flashing case to predict the collapse mechanism, which is discussed in the next section.

The growth of vapour bubbles inside the droplets is described using formulas proposed by Mikic et al. [28] based on non-dimensional time $t^{*}$ and non-dimensional radius $R^{*}$ (Equations (7)-(10)). These correlations include the bubble growth by both inertial forces and heat diffusion:

$$
\begin{gathered}
R^{*}=\frac{2}{3}\left[\left(t^{*}+1\right)^{\frac{3}{2}}-\left(t^{*}\right)^{\frac{3}{2}}-1\right] \\
R^{*}=\frac{R}{B^{2} / A}, t^{*}=\frac{t}{B^{2} / A^{2}}
\end{gathered}
$$




$$
\begin{gathered}
A=\left[\frac{2}{3} \frac{\left(T_{d}-T_{b}\right) L \rho_{v}}{T_{b} \cdot \rho_{l}}\right]^{\frac{1}{2}}, B=\left[\frac{12}{\pi} J a^{2} \alpha\right]^{\frac{1}{2}} \\
J a=\frac{\rho_{l} c_{p l}\left(T_{d}-T_{b}\right)}{L \cdot \rho_{v}}
\end{gathered}
$$

where $\rho_{l}$ is the fuel density; $\rho_{v}$ is the vapour density; $c_{\mathrm{pl}}$ is the fuel constant pressure heat capacity; $J a$ is the Jakob number; $\alpha$ is the liquid thermal diffusivity; and $L$ is the heat of vaporisation.

The effect of enhanced atomisation and droplets' micro explosions is an enhanced spray angle $\beta$. The angle enhancement is described by Equation (11), which is based on the formula of Zuo et al. [24]:

$$
\beta=\beta_{0}+\left(30 \cdot f_{1}-\beta_{0}\right) \cdot \chi^{2}
$$

where $\beta_{0}$ is the input non-flashing spray angle (in this study $14^{\circ}$ ); $f_{1}$ is the correction factor (in this study equals 1 ); and $\chi$ is a superheat-based parameter calculated as follows:

$$
\chi=\frac{c_{p}\left(T_{d}\right) \cdot T_{d}-c_{p}\left(T_{b}\right) \cdot T_{b}}{L\left(T_{b}\right)}
$$

where $c_{p}\left(T_{d}\right)$ and $c_{p}\left(T_{b}\right)$ are constant pressure heat capacities at the droplet and boiling temperature, respectively.

The k- $\zeta$-f turbulence model, developed by Hanjalić et al. [29], was used as recommended for engine simulations using AVL FIRE ${ }^{\mathrm{TM}}$ software.

The constant volume chamber was represented by the domain of a cylindrical shape of $150 \mathrm{~mm}$ diameter and $150 \mathrm{~mm}$ height. A polyhedral element shape was used to limit the errors associated with the jet going along the cell interfaces, using a Cartesian type element [30,31]. The mesh was created with a base cell size of $3 \mathrm{~mm}$ and used with an additional conical refinement to $0.75 \mathrm{~mm}$. Figure 5 illustrates a half-section view of the mesh. The injected mass was calculated using a measured initial velocity which was derived from the averaged spray penetration during the first $0.5 \mathrm{~ms}$ of the injection events:

$$
\dot{m}=\rho \cdot A_{n} \cdot v
$$

where $\dot{m}$ is the fuel mass flow; $A_{n}$ is the area of injector nozzles; and $v$ is the injection velocity. The injector has a step-hole nozzle design. To calculate the mass flow rate, the inner diameter was used. The outer diameter was used as an input in the CFD to provide the correct initial positioning of the droplets.

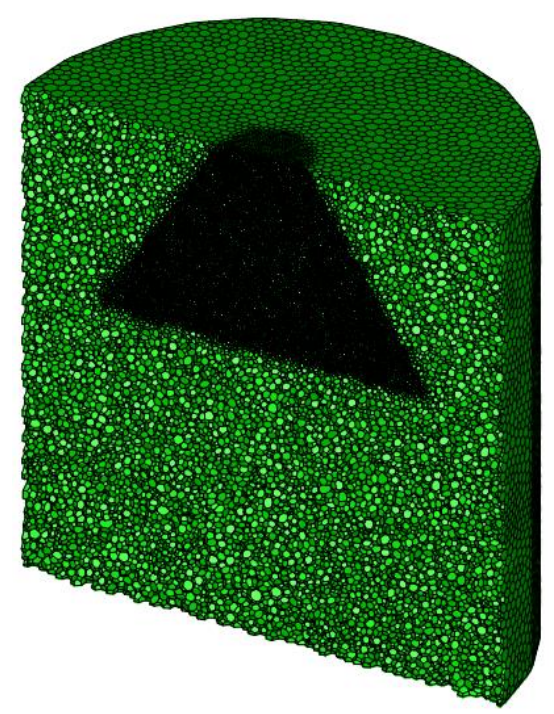

Figure 5. Computational mesh half-section view. 
As the experimental research was based on Schlieren imaging, the vapour penetration was used as the calibration parameter. The threshold was set to $0.1 \%$ of the fuel vapour mass fraction.

The numerical simulations were performed for selected cases, including the highest and the lowest considered injection pressures. Table 1 lists all calculation cases along with the initial spray velocity $\boldsymbol{v}_{\text {spray }}$ and injected mass for a considered injection duration ( $\left.2 \mathrm{~ms}\right)$ $m_{\text {injected }}$.

Table 1. Analysed CFD cases with calculated spray velocities and injected mass.

\begin{tabular}{ccccc}
\hline Case & $p_{\text {inj }}[\mathbf{M P a}]$ & $p_{\text {amb }}[\mathrm{MPa}]$ & $\boldsymbol{v}_{\text {spray }}[\mathbf{m} / \mathbf{s}]$ & $m_{\text {injected }}[\mathbf{m g}]$ \\
\hline 1 & 14 & 0.1 & 118.3 & 138.6 \\
2 & 14 & 0.5 & 106.1 & 124.3 \\
3 & 14 & 1 & 80.7 & 94.5 \\
4 & 14 & 2 & 47.6 & 87.4 \\
5 & 2 & 0.1 & 52.7 & 61.7 \\
6 & 6 & 0.1 & 89.3 & 104.6 \\
\hline
\end{tabular}

\section{Results and Discussion}

The results concern both the experimental and numerical part of the study, and therefore they are presented in separate subsections.

\subsection{Experiments}

The experiments were obtained in two stages. In the first part of the study, for the maximum considered injection pressure (14 MPa), a series of measurements were taken for different ambient pressures (0.1-6 MPa) to compare penetration curves at subcooled and flash-boiling conditions. In the second part, the effect of injection pressure was studied at three different levels of ambient pressure $(0.1,2$ and $6 \mathrm{MPa})$. Note that all pressures are absolute. The results from these two parts are presented in the following two separate subsections.

\subsubsection{Ambient Pressure Effect}

In this subsection, the effect of flash boiling on the structures of liquid propane sprays is analysed in terms of trends observed for subcooled conditions. As liquid propane in the ambient environment is superheated, and here its temperature was kept constant, a wide range of ambient pressures was considered to reach subcooled conditions. Figure 6 shows selected raw Schlieren images of the sprays obtained at different ambient pressures. Despite a different spray penetration, which could be associated with a changing ambient density and the pressure difference, there is also an apparent effect related to the flash boiling in the form of a large amount of generated vapour. Additionally, a substantial spray collapse is observed for the lowest ambient pressure (and the highest $R_{p}=8.36$ ). A collapse is visible already at $p_{a m b}=0.2 \mathrm{MPa}\left(R_{p}=4.18\right)$, influencing the spray-tip penetration and the spray angle, which will be discussed later.

Figure 7 shows the spray-tip penetration obtained at different ambient pressures. Each curve is an average from three repetitions. The results clearly show that the penetration values are strongly influenced by flash boiling. When the ambient pressure is reduced from 2 to $1 \mathrm{MPa}$, the difference is much lower than in the case of a pressure reduction from 1 to $0.5 \mathrm{MPa}$. A further decrease of the ambient pressure does not influence the penetration much, indicating a similar flash boiling effect. It needs to be taken into account that the pressure difference between the injection and ambient pressure $\Delta p$ changes with the changing ambient pressure. However, for low ambient pressures, i.e., 0.5, 0.2 and 0.1, the maximum relative change of the $\Delta p$ is less than $3 \%$, which is assumed to be marginal, and the effect of the changing ambient pressure will be dominant. 


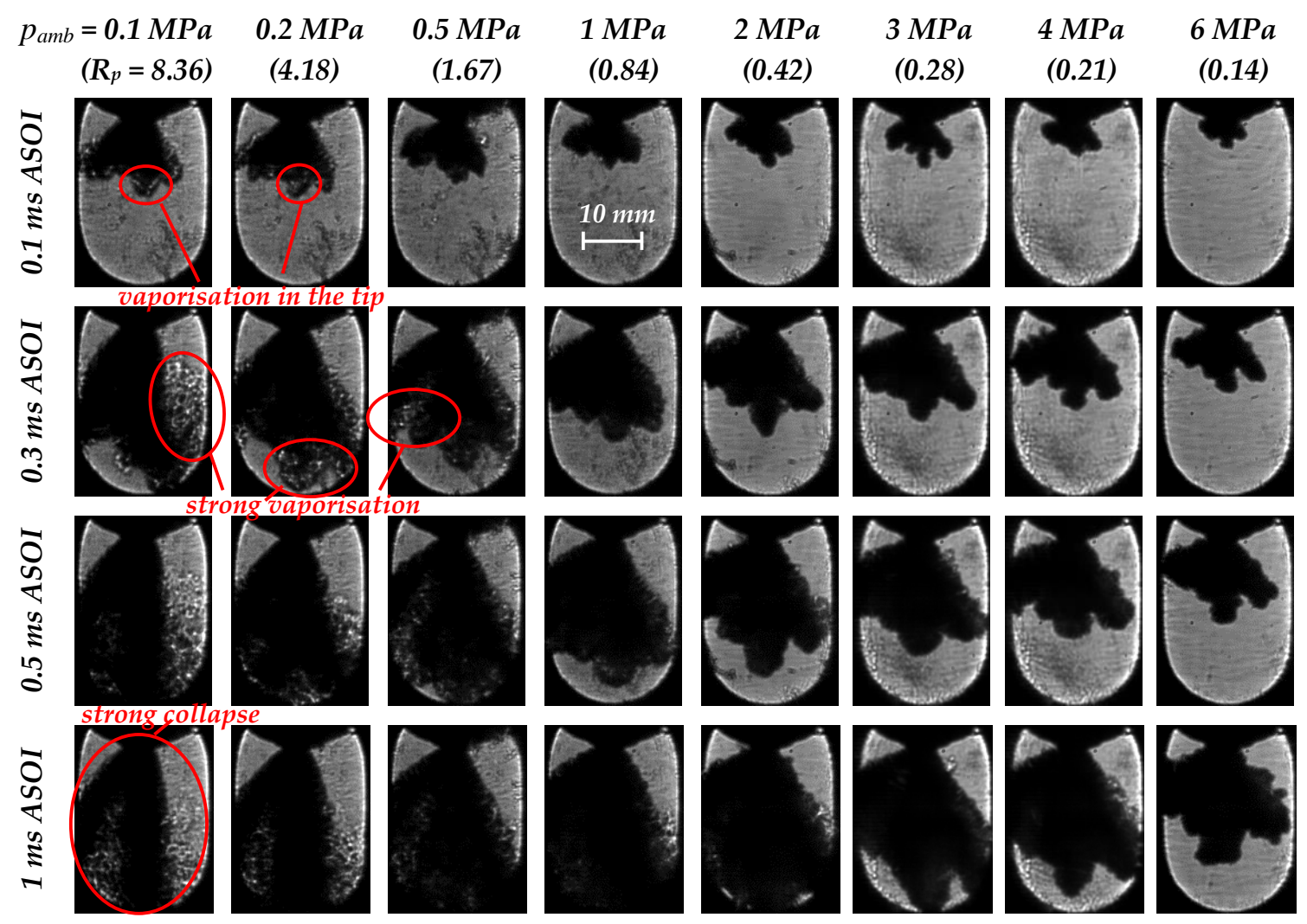

Figure 6. The selected images obtained at different ambient pressures; $p_{i n j}=14 \mathrm{MPa}$.

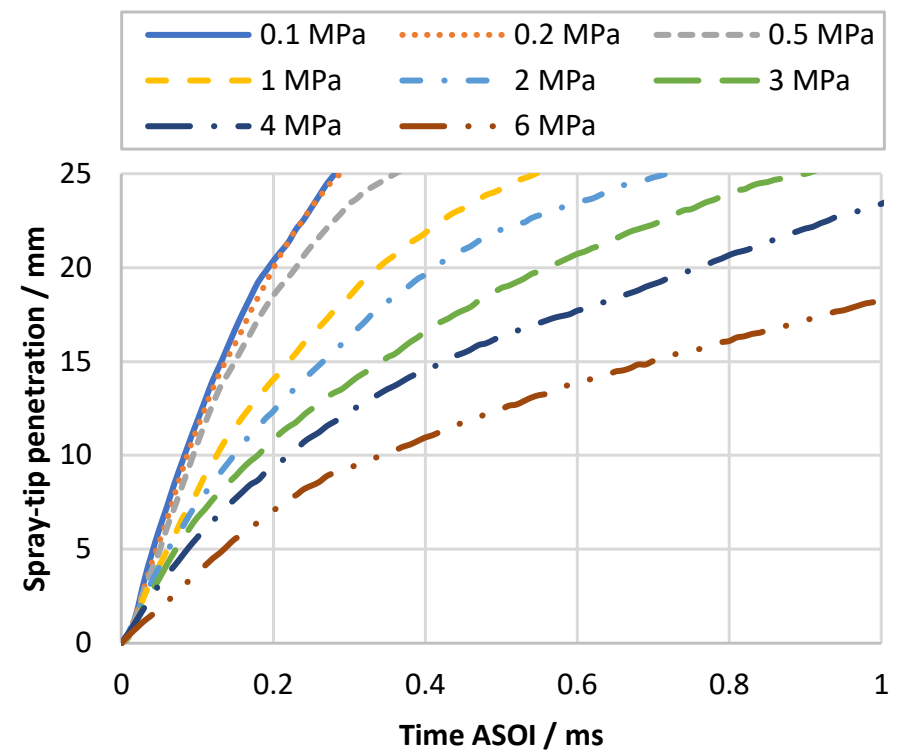

Figure 7. Spray-tip penetration for different ambient pressures-average for three injection events; $p_{\text {inj }}=14 \mathrm{MPa}$.

Although the curves show very similar characteristics, the penetration is strongly influenced by the flash boiling in a way that the changing ambient pressure cannot explain alone. Figure 8 shows the comparison of the spray-tip penetration 0.1 and $0.25 \mathrm{~ms}$ after the start of injection (ASOI). 


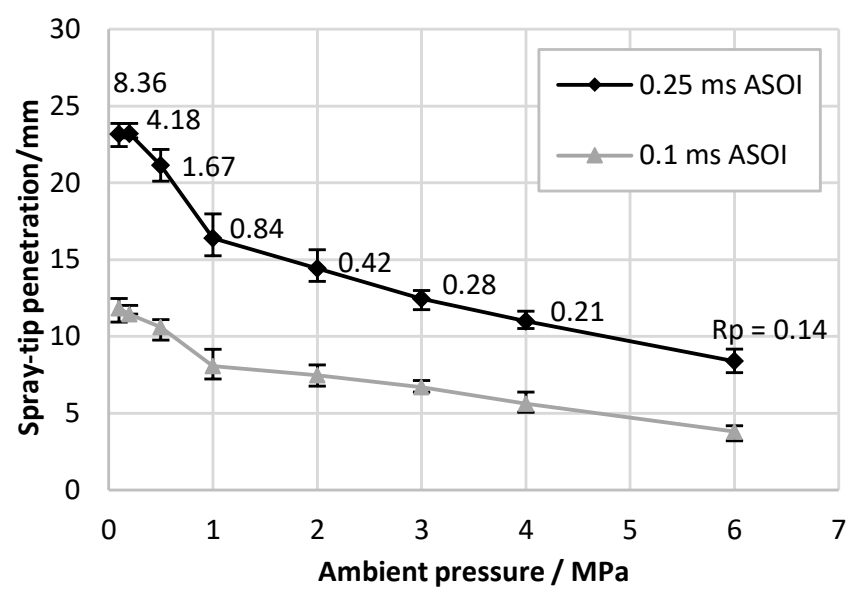

Figure 8. Spray-tip penetration at 0.1 and $0.25 \mathrm{~ms}$ ASOI versus ambient pressure-average for three injection events; $p_{i n j}=14 \mathrm{MPa}$; maximum and minimum values in the series were shown as error bars; $R_{p}$ values apply to both curves for the corresponding ambient pressures.

The two curves presented in Figure 8 show a similar dependence on the ambient pressure. For subcooled conditions $\left(R_{p}<1\right)$, both curves are close-to-linear; while for flash-boiling conditions $\left(R_{p}>1\right)$, the dependence changes drastically, leading to a higher spray-tip penetration than expected from the subcooled trends. This is related to the additional momentum source from the expanding bubbles and bursting droplets and ligaments. Moreover, the spray images (Figure 6) also show a vapour phase in the tip area for the flash-boiling cases, which enhances the penetration (determined by the Schlieren method) as well.

The spray angle was dependent on time. The values at the initial stage of the injection process were substantially different from the values determined for the developed sprays, which is a typical feature. However, due to the low resolution of the captured images, the spray angle could not be determined in a reliable way in the initial stage when the spray clouds were very small. Thus, in Figure 9, showing the evolution of the spray angle, only the results obtained $0.2 \mathrm{~ms}$ ASOI and later are presented.

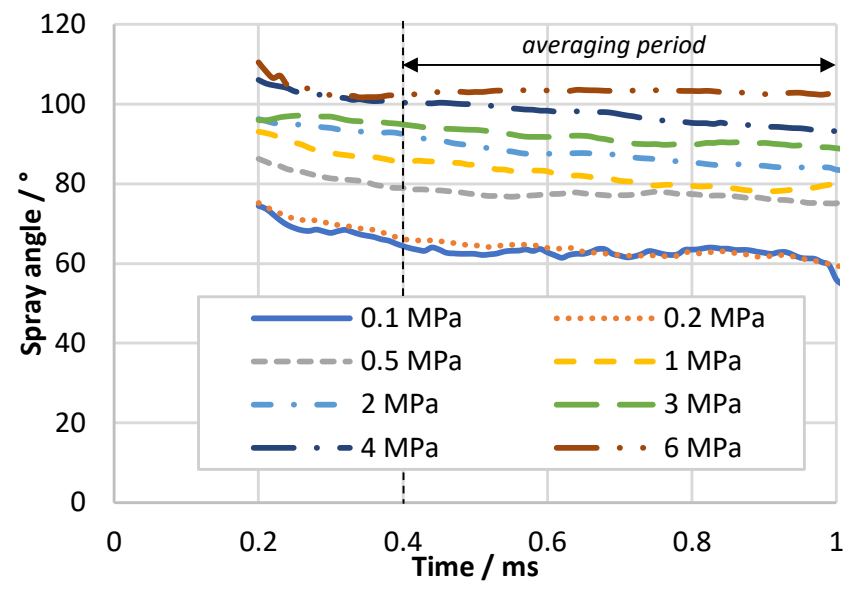

Figure 9. Spray angle evolution for different ambient pressures-average for three injection events; $p_{\text {inj }}=14 \mathrm{MPa}$.

To compare the spray angles quantitatively, both values, the instantaneous (obtained $0.25 \mathrm{~ms}$ ASOI) and the time-averaged (between 0.4 and $1 \mathrm{~ms} \mathrm{ASOI),} \mathrm{were} \mathrm{plotted} \mathrm{against}$ the ambient pressure (Figure 10). 


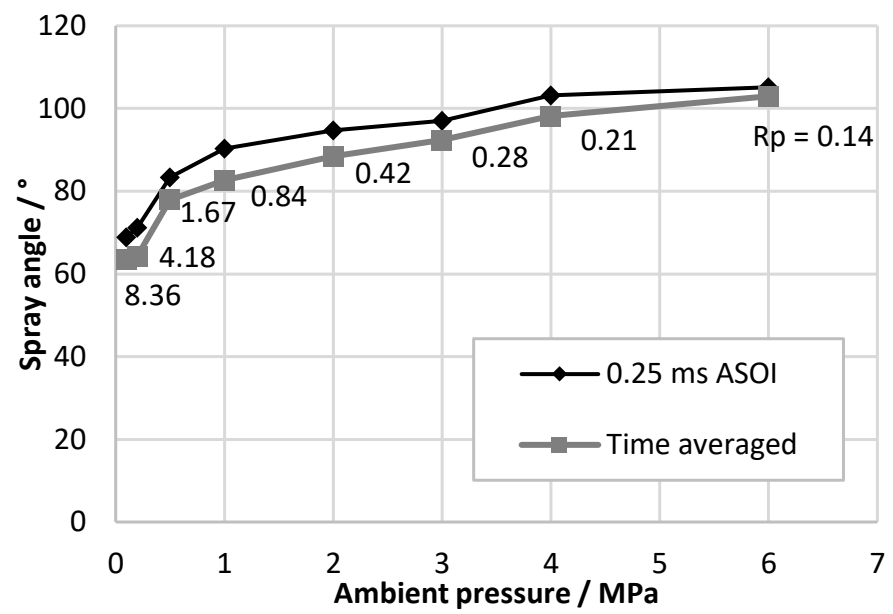

Figure 10. Spray angle $0.25 \mathrm{~ms}$ ASOI and the time-averaged values $(0.4-1 \mathrm{~ms})$ versus ambient pressure-average for three injection events; $p_{i n j}=14 \mathrm{MPa} ; R_{p}$ values apply to both curves for the corresponding ambient pressures.

The curves presented in Figure 10 show that the drastic change in the spray angle is observed in the flash-boiling regime. The instantaneous values obtained $0.25 \mathrm{~ms}$ ASOI suggest that the first stronger reduction of the angle is observed in the $R_{p}$ range $0.84-1.67$. The average values indicate a rapid change for $R_{p}$ between 1.67 and 4.18. Despite this difference, the overall effect of the ambient pressure on the spray angle, regardless of the angle definition, is very similar and clearly indicates a crucial role of flash boiling. These observations are in line with the results of the spray-tip penetration (Figure 8).

\subsubsection{Injection Pressure Effect}

As for the injection pressure, its effects were investigated at three different ambient pressures, namely, $0.1,2$ and $6 \mathrm{MPa}$. A pressure of $0.1 \mathrm{MPa}$ was selected for flash-boiling conditions due to the highest $R_{p}$ and the most substantial effects of flash boiling on spray formation (see Figure 6).

Figure 11 shows selected raw Schlieren images of the sprays obtained for different injection pressures for subcooled conditions $\left(p_{a m b}=2\right.$ and $\left.6 \mathrm{MPa}\right)$. The subcooled cases served as reference cases for further investigation of the possible interaction between the flash boiling and the injection pressure, when the injection pressure is strongly reduced compared to the typical conditions of SIDI engines. The effect of injection pressure for the subcooled sprays is manifested mainly by the different penetrations, while the angles are similar. The shapes of the sprays are similar, and the sprays seem to just develop at a different rate depending on the injection pressure. Moreover, this is observed for both considered ambient pressures. For example, the spray obtained at $p_{a m b}=2 \mathrm{MPa}, p_{i n j}=6 \mathrm{MPa}$ at $0.5 \mathrm{~ms}$ ASOI is similar to the spray obtained at $p_{a m b}=2 \mathrm{MPa}$, $p_{i n j}=10 \mathrm{MPa}$ at $0.3 \mathrm{~ms}$ ASOI, and the spray obtained at $p_{a m b}=6 \mathrm{MPa}, \mathrm{p}_{\mathrm{inj}}=8 \mathrm{MPa}$ at $0.5 \mathrm{~ms}$ ASOI is similar to the spray recorded at $p_{a m b}=6 \mathrm{MPa}, p_{i n j}=10 \mathrm{MPa}$ at $0.3 \mathrm{~ms}$ ASOI. No significant differences between the sprays can be observed. The only difference between the two considered ambient pressures is visible vaporisation at lower ambient pressure $\left(p_{a m b}=2\right)$ for all injection pressures, but most evidently for the highest injection pressure. However, the evaporation was not significant and did not have a substantial influence on the spray shape. 


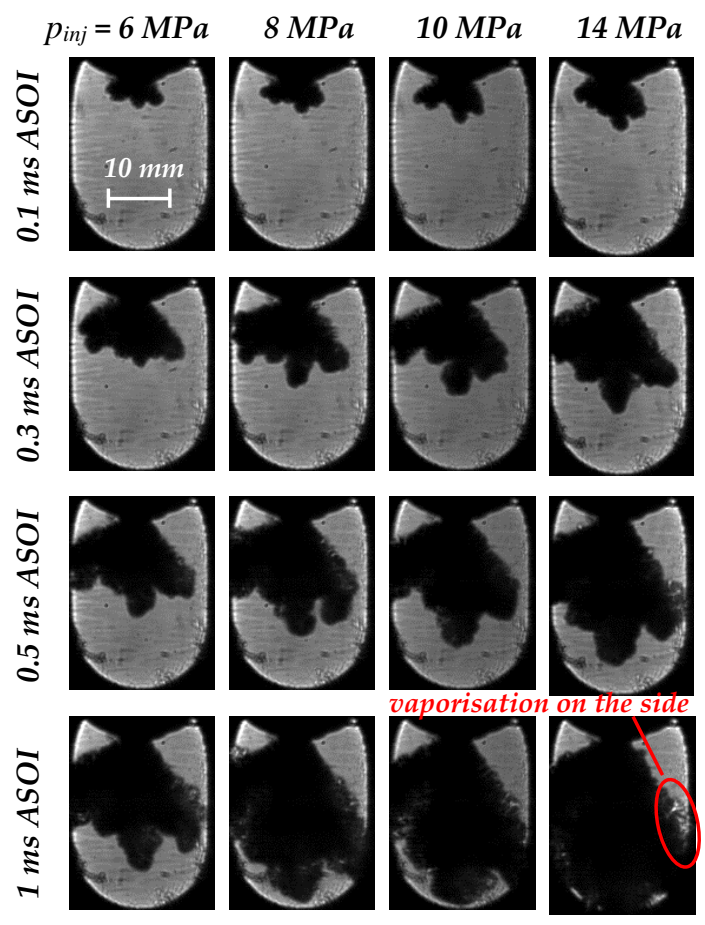

(a)
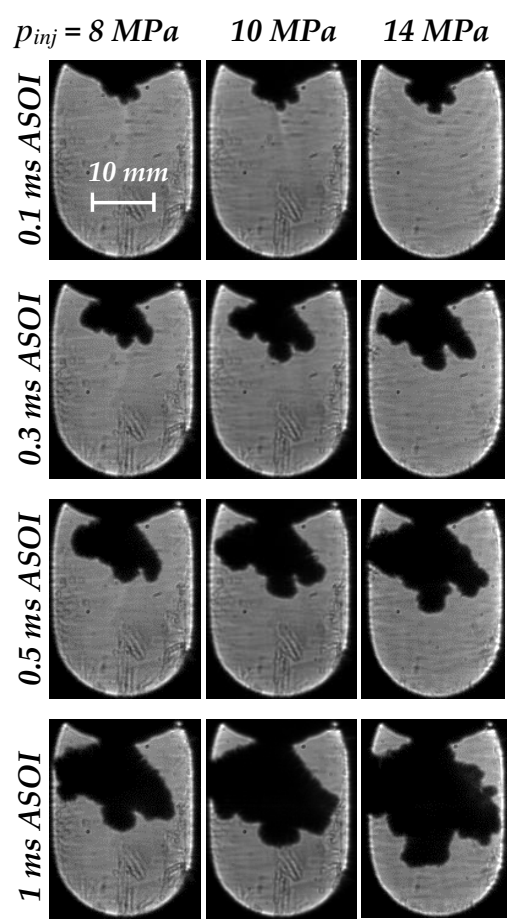

(b)

Figure 11. The selected images obtained at different injection pressures: (a) $p_{a m b}=2 \mathrm{MPa}\left(R_{p} \approx 0.42\right)$; (b) $p_{a m b}=6 \mathrm{MPa}\left(R_{p} \approx 0.14\right)$.

At lower ambient pressure, the spray formation changes dramatically. Figure 12 shows selected raw Schlieren images of the sprays obtained for different injection pressures at ambient pressure $0.1 \mathrm{MPa}$. Despite a different spray penetration, there is also an apparent effect related to flash boiling in the form of a large amount of generated vapour. The vapour is visible around the spray cloud regardless of the injection pressure. However, for the lowest injection pressures, it is the most evident. Moreover, the vapour phase exceeds the liquid phase in influencing the spray-tip penetration for the lowest injection pressures. The strong presence of the vapour in the tip area for the lowest injection pressure should be linked with the expected lower injection velocity. The vapour also appears on the sides of the spray cloud, and a vortex is created, but ultimately the sprays collapse regardless of the injection pressure, and the final structures of the sprays are very similar to each other. This is in accordance with the results of Kim et al. [18] obtained for a six-hole injector and very different from the observations made by Poursadegh et al. [16] for an eight-hole injector. Kim et al. [18] showed that the spray structures were similar regardless of the injection pressure, with a slightly increased spray-tip penetration for higher injection pressures. Poursadegh et al. [16] reported a strong influence from the injection pressure on the spray formation, and it was dependent on the conditions. For a fuel temperature of $360 \mathrm{~K}$ and an ambient pressure of $50 \mathrm{kPa}$, the sprays strongly collapsed, and the higher injection pressure led to a higher plume expansion. At the ambient pressure of $0.1 \mathrm{MPa}$, the effects of the injection pressure were different. For the injection pressure of $4.5 \mathrm{MPa}$, the spray collapsed, but individual plumes could still be distinguished. When the injection pressure was increased to $7 \mathrm{MPa}$, the spray fully collapsed and formed a single jet-like structure. For an even higher injection pressure (20 MPa), this single jet-like structure was expanded. These different observations may be the result of near-critical effects. At the temperature of $360 \mathrm{~K}$, liquid propane is much more compressible compared to the temperature set in this study or in the experiments of Kim et al. [18], i.e., 294 and 293 K, respectively (see Figure 3). Moreover, the $R_{p}$ was substantially different (35.55 for the ambient pressure $0.1 \mathrm{MPa}$ and the fuel temperature $360 \mathrm{~K}$ ). A different configuration of the injector could play a role as well. 


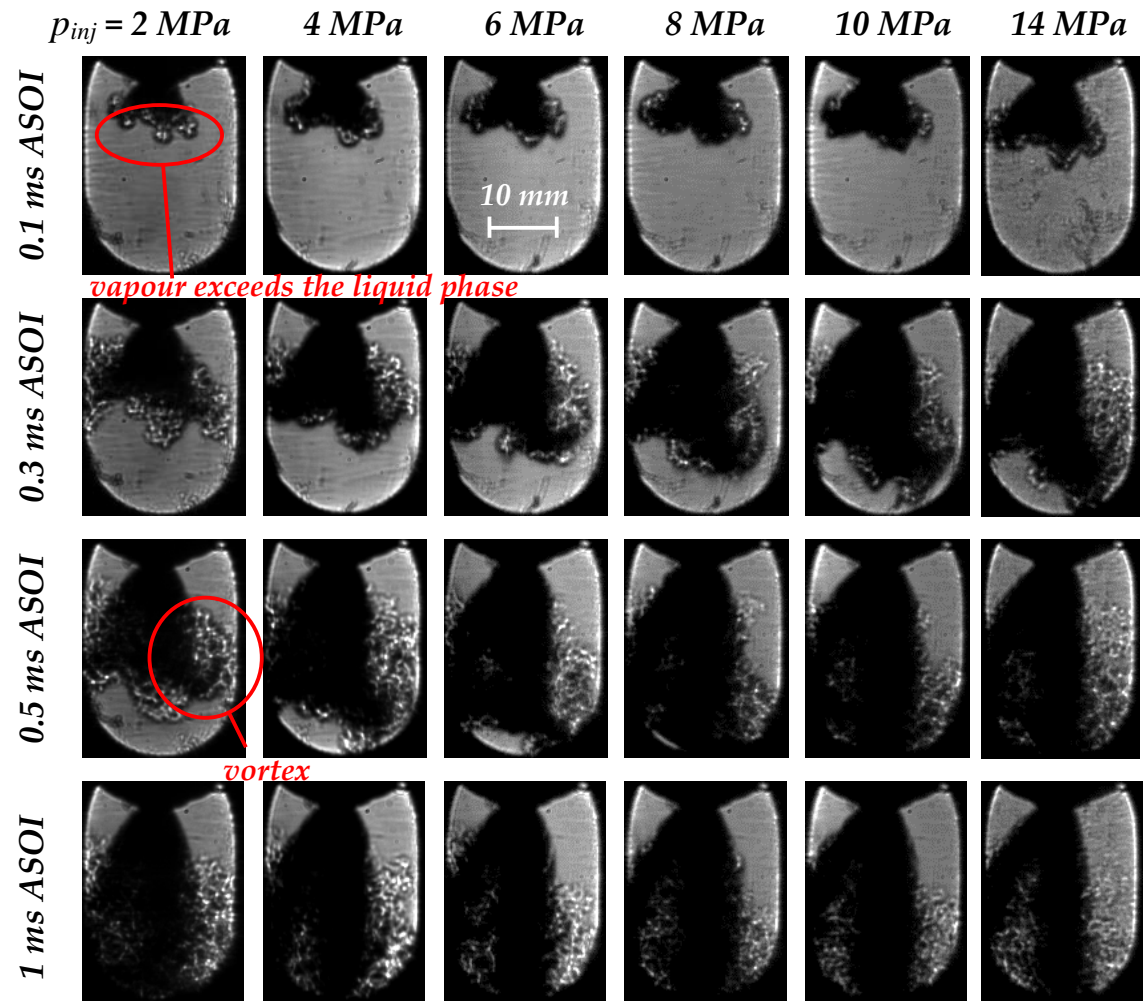

Figure 12. The selected images obtained at different injection pressures; $p_{a m b}=0.1 \mathrm{MPa},\left(R_{p} \approx 8.36\right)$.

Figures 13-15 show the spray-tip penetration obtained at ambient pressures of 0.1, 2 and $6 \mathrm{MPa}$, respectively. Figure 13 shows the effect of injection pressure in flashboiling conditions; while Figures 14 and 15 refer to the subcooled cases. Despite very different penetration values, the results suggest a very similar injection pressure influence on the spray-tip penetration. Moreover, the curves are similar with only one in which it might be argued that a two-stage spray development can be observed (Figure 15, $\left.p_{a m b}=6 \mathrm{MPa}, p_{i n j}=14 \mathrm{MPa}\right)$.

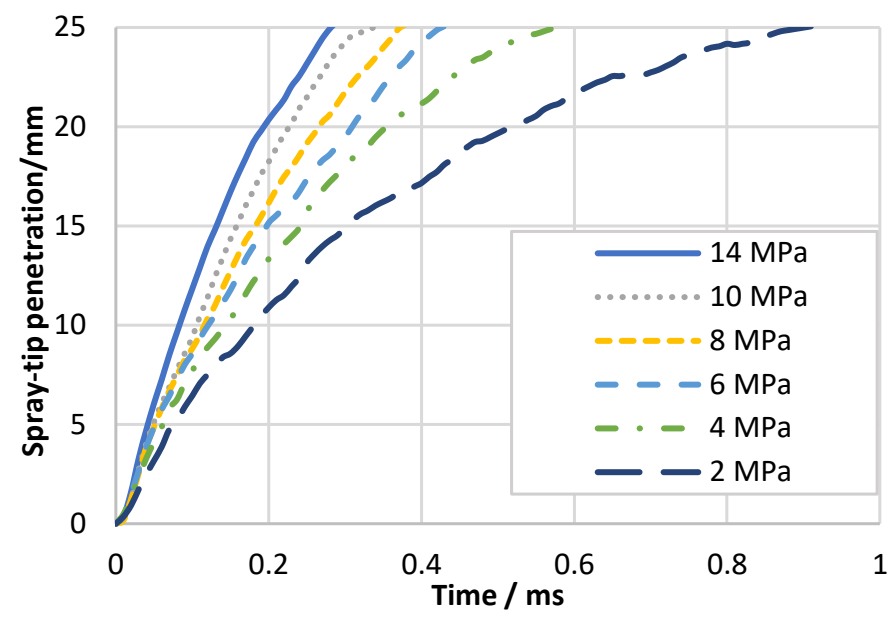

Figure 13. Spray-tip penetration for different injection pressures-average for three injection events; $p_{a m b}=0.1 \mathrm{MPa}\left(R_{p}=8.43\right)$. 


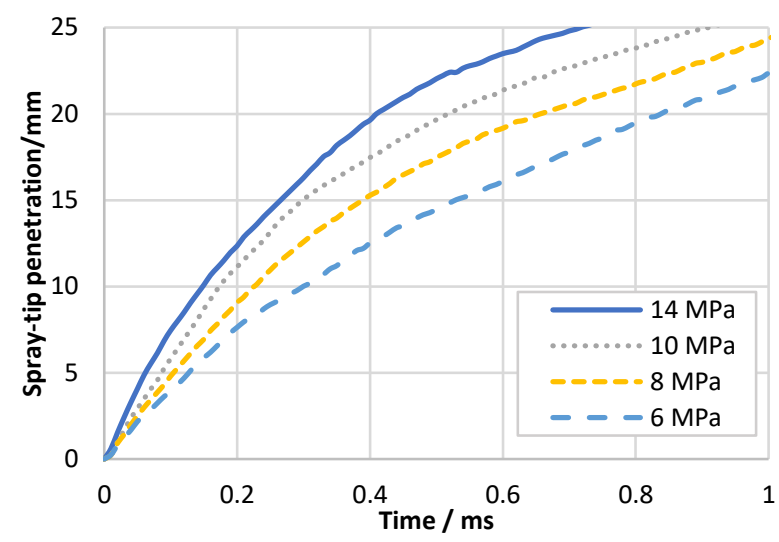

Figure 14. Spray-tip penetration for different injection pressures-average for three injection events; $p_{a m b}=2 \mathrm{MPa}$.

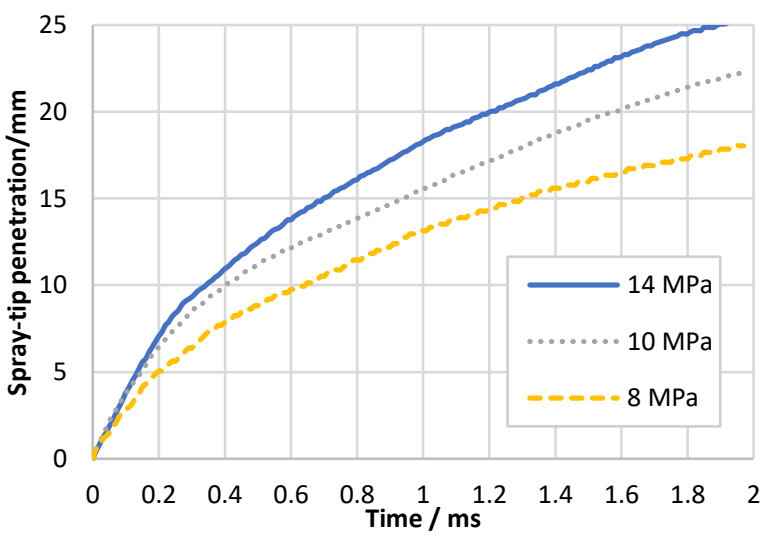

Figure 15. Spray-tip penetration for different injection pressures-average for three injection events; $p_{a m b}=6 \mathrm{MPa}$.

Figure 16 compares the spray-tip penetration $s$ at $0.25 \mathrm{~ms}$ ASOI for three considered ambient pressures. The results showed a close-to-linear dependence of the angle, regardless of the ambient pressure and whether or not there is flash boiling. An interesting feature is that the slope of the linear-fit functions is proportional to the ambient pressure, which could suggest no specific effect from flash boiling. However, this shall be treated as a coincidence; as there are only three levels of ambient pressure, one cannot make a serious conclusion from such a correlation.

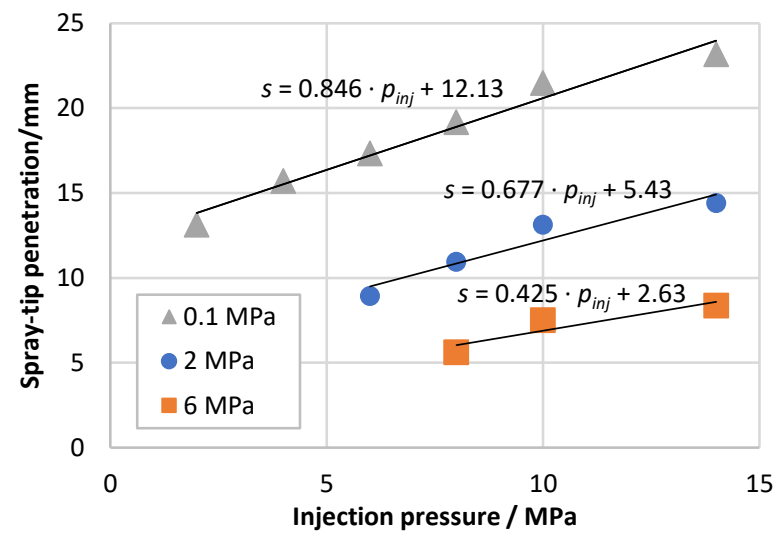

Figure 16. Spray-tip penetration at $0.25 \mathrm{~ms}$ ASOI versus injection pressure for different ambient pressures-average for three injection events; $s$ stands for spray penetration. 
A common feature of the studies on spray-tip penetration formed by round nozzles is to report spray penetration as a function of the pressure difference between the injection and ambient pressures $\Delta p$ [32-35]. Only a fraction of researchers use injection pressure instead of $\Delta p$, e.g., [36,37]. Moreover, the spray-tip penetration is reported as a power function of $\Delta p$ with an exponent of 0.25 [32-35] (in [34] only in the second stage-after the break-up). Figure 17 compares the experimental results of the spray penetration at $0.25 \mathrm{~ms}$ ASOI versus $\Delta p$ for different ambient pressures with the power-fit functions of $\Delta p$ (assuming an exponent of 0.25).

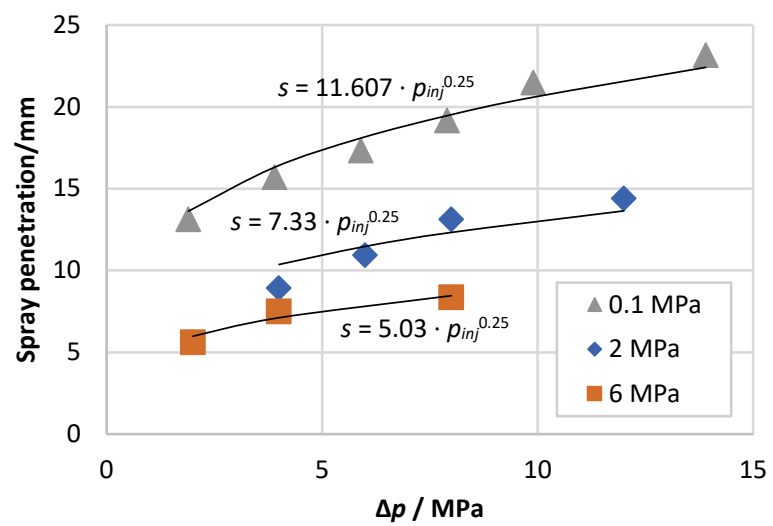

Figure 17. Spray-tip penetration at $0.25 \mathrm{~ms}$ ASOI versus $\Delta p$ for different ambient pressures—average for three injection events; $s$ stands for spray penetration.

One should not focus on the coefficients. The idea behind this comparison is not to develop the fit functions and to provide specific values of the constants, as these would apply only to the current set-up. The goal is to verify if similar trends for the subcooled and flash-boiling conditions can be observed when at constant ambient pressure the $\Delta p$ is then changed.

The results for flash-boiling cases shown in Figure $17\left(p_{a m b}=0.1 \mathrm{MPa}\right)$ follow the trend very well. The power fit (with the assumption of an exponent equal to 0.25 ) offers a higher coefficient of determination $\left(\mathrm{R}^{2}=98.38 \%\right)$ compared to the linear fit shown in Figure 16 $\left(R^{2}=97.06 \%\right)$ for the same group of results. For the subcooled cases, $R^{2}$ is also higher for the power fit: 96.71 versus 91.73 and 93.55 versus 85.05 for the ambient pressure of 2 and $6 \mathrm{MPa}$, respectively. It might be speculated that the trend lines lie pretty far from the experimental results and the coefficients of determination are relatively low, especially in the subcooled cases. However, it is well established that the penetration is a power function of $\Delta p$ with an exponent of 0.25 for subcooled cases. The critical question to answer is whether the same correlation is observed for highly flashing conditions. The results obtained here clearly confirm such behaviour. In flash-boiling conditions $\left(p_{a m b}=0.1 \mathrm{MPa}\right)$, the number of the studied injection pressures is the highest. Thus, the fit and calculated coefficient of determination should be considered reliable.

As for the spray angle $(\alpha)$, Figure 18 shows its minor dependence on the injection pressure. The values obtained at constant ambient pressure are similar, and only for the flash-boiling cases does the angle differ by $10^{\circ}$ between the minimum and maximum values, obtained respectively for 2 and $14 \mathrm{MPa}$ injection pressure. It is generally expected that the spray angle would decrease with injection pressure due to a higher axial momentum. However, in this case, the angle is measured using the Schlieren technique, in which the vapour phase plays a crucial role. Higher injection pressure is expected to be linked with higher mass injected and more rapid flash-vaporisation, which enhances the angle. Moreover, in this study, the angle of the whole spray cloud is measured instead of a single plume. Much smaller values for the flash-boiling cases $\left(\mathrm{p}_{\mathrm{amb}}=0.1 \mathrm{MPa}\right)$ clearly indicate that a spray collapse is observed, which corresponds with the results reported in Figure 10. That also could be a reason for the slightly different trends in the spray angle depending on the conditions. 


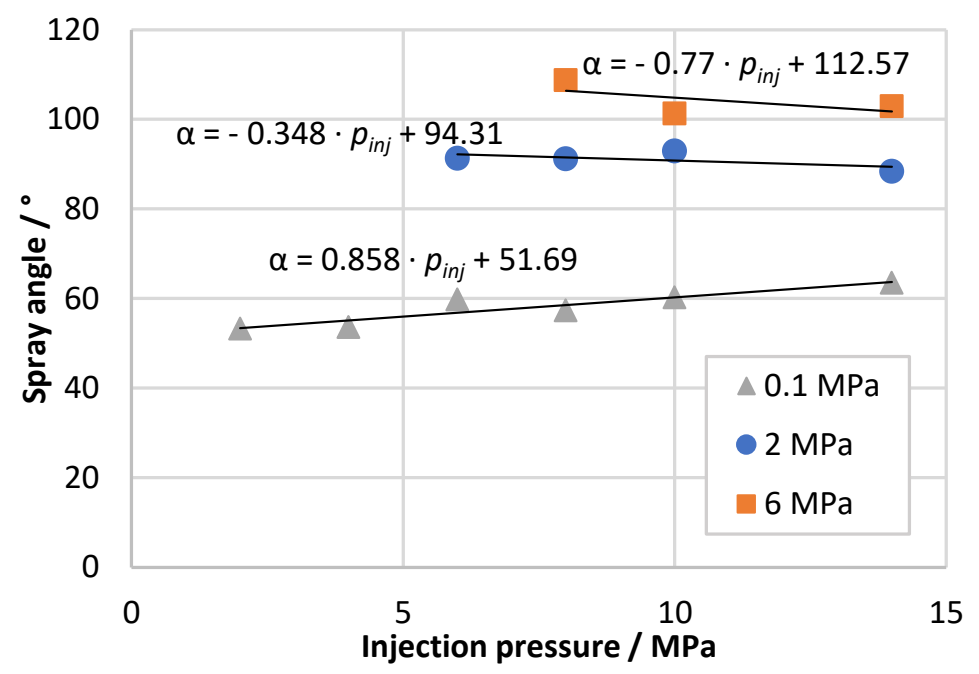

Figure 18. Spray angle (time-averaged $0.4-1 \mathrm{~ms}$ ) versus injection pressure for different ambient pressures-average for three injection events.

The angle of sprays formed by a single nozzle is generally assumed to depend on the gas-to-liquid density ratio $[34,38,39]$. As the gas density for each series is constant, the liquid density will be the only changing factor. Based on Figure 3, one may notice that the density of liquid propane will change very little with the injection pressure at the considered temperature. The extreme values of the propane density were 528.5 and $500.2 \mathrm{~kg} / \mathrm{m}^{3}$ for injection pressures of 14 and $2 \mathrm{MPa}$, respectively. This would explain only minor changes in the spray angle.

In general, it may be concluded that despite a strong influence of the flash boiling on both spray-tip penetration and spray angle, the influence of injection pressure on propane sprays is very similar for both conditions, subcooled and flash boiling.

\subsection{Numerical Simulations}

The numerical model was calibrated for selected cases, including the highest and the lowest considered injection pressures. The critical element of the model was the correction factor $f_{2}$ for the bubble number density (Equation (6)). There was no universal value resulting in proper representation of the spray collapse, and it needed to be adjusted separately for each flashing case. Figure 19 shows the stochastic representation of droplet clouds for ambient pressures of 0.1 and $0.5 \mathrm{MPa}$ for two spray set-ups: with the default setting of the correction factor $\left(f_{2}=1\right)$; and after individual calibration (modified). It is visible that for the lower value of the correction factor $f_{2}$ (resulting in the lower number of bubbles), the spray collapse is not predicted for the high-superheat case. The higher value of the factor leads to an entirely different spray structure, resembling a collapsed cloud. For the ambient pressure of $0.5 \mathrm{MPa}$, the increased number of bubbles results in enhanced spray dispersion in the vortex area. Note that the selected value of the factor for this ambient pressure was ten times lower than for the $0.1 \mathrm{MPa}$ case.

Figure 20 illustrates the calculated spray vapour penetration and the experimental results described in previous chapters. In the flare flash-boiling case $\left(p_{a m b}=0.1 \mathrm{MPa}\right)$, the results are similar. However, in the rest of the cases, the spray-tip penetration is underestimated by the model. As it can be noticed, the simulation curves are more linear than the experimental curves. 


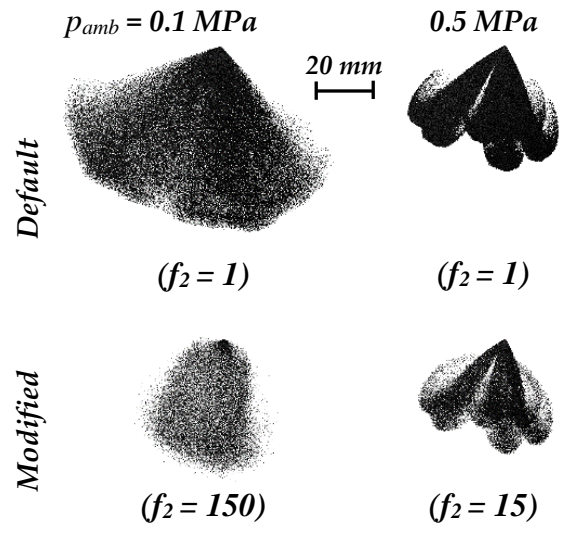

Figure 19. Numerical results—stochastic representation of droplet clouds obtained at $1 \mathrm{~ms}$ ASOI for different correction factors and ambient pressures; $p_{i n j}=14 \mathrm{MPa}$.

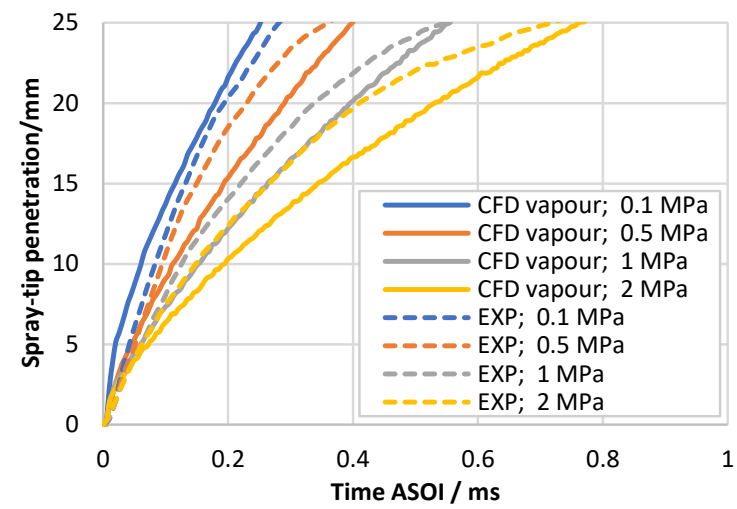

Figure 20. Spray-tip penetration at different ambient pressures: vapour penetration from CFD simulations and the experimental results; $p_{i n j}=14 \mathrm{MPa}$.

It could be speculated as to whether the penetration in the simulations should be determined based on the droplets (liquid phase) instead of the vapour phase. Figure 21 shows that the difference between the liquid and vapour spray penetration for a fixed injection pressure (14 $\mathrm{MPa})$ is not substantial. With the decreasing ambient pressure, the liquid penetration gets closer to the gas penetration. For the ambient pressure of $0.1 \mathrm{MPa}$, the liquid and vapour penetrations are almost the same, representing the experimental results very well. As the pressure in the ambient environment decreases, the superheat increases. The bubbles inside the droplets enlarge faster, and the velocity compound of the new droplets increases. Thus, the flash boiling enhances the velocity of the droplets and leads to a higher liquid penetration.

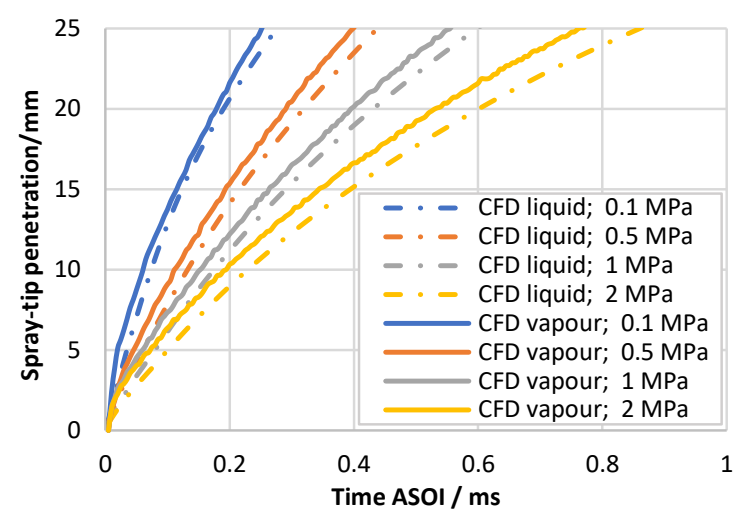

Figure 21. Comparison of liquid and vapour spray penetration for different ambient pressures; $p_{i n j}=14 \mathrm{MPa}$. 
In Figure 22, the spray clouds obtained in CFD simulations are compared with the Schlieren images. It can be noticed that for the lower ambient pressure, the spray becomes more dispersed with an increased angle and penetration. When the ambient pressure decreased from 1 to $0.5 \mathrm{MPa}$, the spray became much more diluted due to the lower density of the gas and flash-boiling atomisation. At the ambient pressure of $0.1 \mathrm{MPa}$, a single spray cloud with uniformly distributed droplets without separated plumes is formed. However, spray collapse at this stage is lacking, even though it is observed after a longer period of time after the start of the injection (Figures 19 and 23).

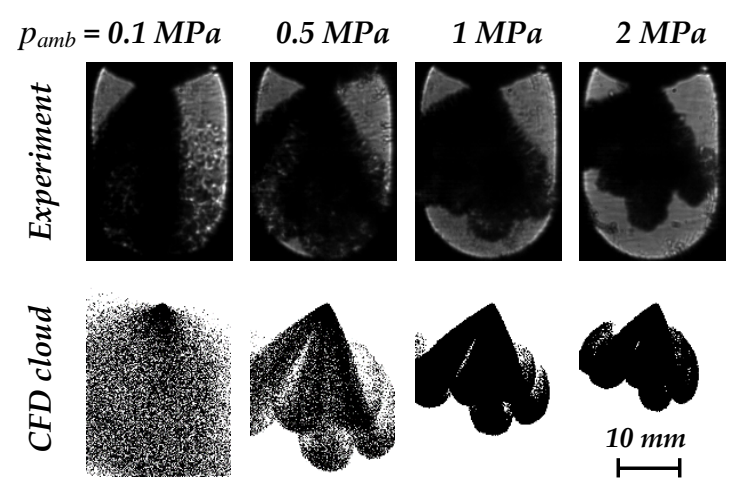

Figure 22. Comparison of experimental results and CFD spray cloud representation at $0.5 \mathrm{~ms}$ ASOI; $p_{\text {inj }}=14 \mathrm{MPa}$.

$0.2 \mathrm{~ms} A \mathrm{SO}$
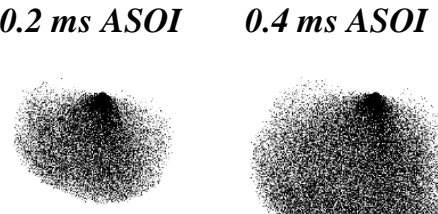

$10 \mathrm{~mm}$
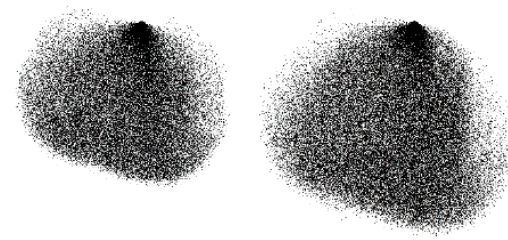

$0.8 \mathrm{~ms}$ ASOI

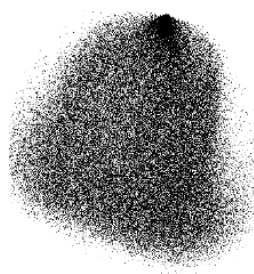

1 ms ASOI

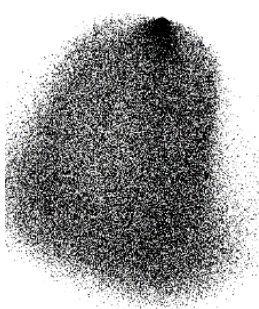

Figure 23. Evolution of the droplet cloud-numerical representation; $p_{i n j}=14 \mathrm{MPa}, p_{a m b}=0.1 \mathrm{MPa}$.

Figure 23 shows the evolution of the spray cloud for the flare flash-boiling conditions $\left(p_{a m b}=0.1 \mathrm{MPa}\right)$. As it can be noticed, the spray collapse is ultimately occurring. However, the flare-flashing cloud is wider than in the experimental images (see Figure 6).

Figure 24 shows the calculated liquid and vapour penetration together with the experimental results obtained for different injection pressures under flare flash-boiling conditions $\left(p_{a m b}=0.1 \mathrm{MPa}\right)$. For the highest injection pressure $(14 \mathrm{MPa})$, both penetrations from the numerical simulations show strong similarities with the experiments, and only a slight difference for the vapour phase can be observed. However, the overestimation of the penetration determined by the vapour phase is increased for the lower injection pressures. It is presumedly due to the same evaporation rate and the droplet acceleration from the flash-boiling atomisation. The liquid penetration predicts the experimental results very well regardless of the injection pressure.

Figure 25 shows the comparison of the numerically represented spray clouds with the Schlieren images for different injection pressures under flare flash-boiling conditions $\left(p_{a m b}=0.1 \mathrm{MPa}\right)$. The overall spray shape is similar, and no changes in the mechanism of the spray collapse can be noticed. Under lower injection pressure (2 MPa), the spray collapse is more visible due to a shorter spray penetration than in the other cases. 


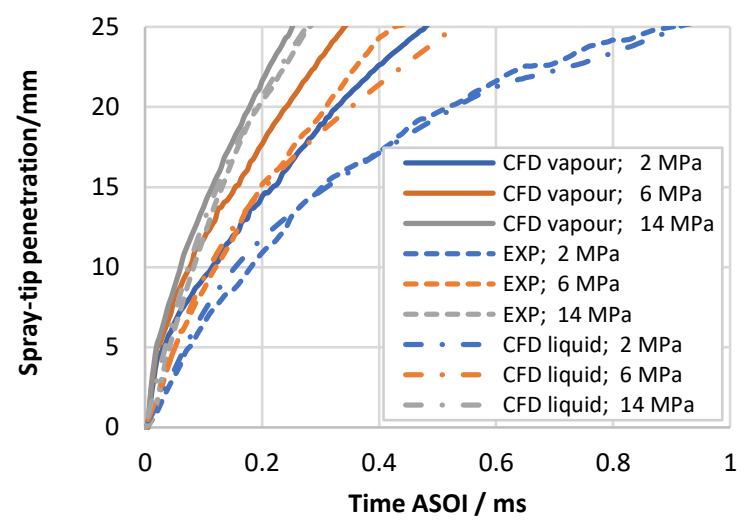

Figure 24. Spray penetration from CFD simulations (vapour and liquid) and the experimental results for different injection pressures; $p_{a m b}=0.1 \mathrm{MPa}$.

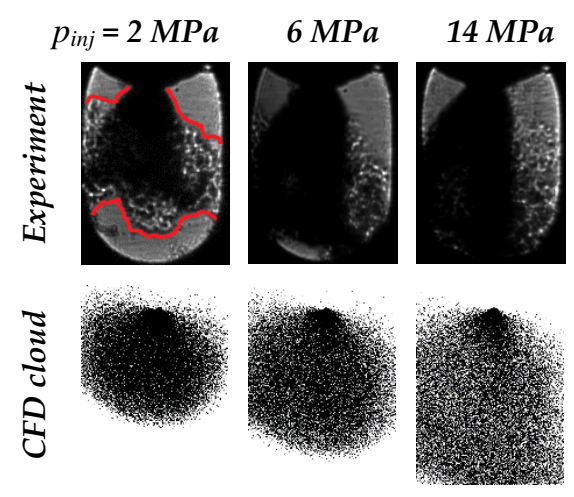

Figure 25. Comparison of experimental results and CFD spray cloud representation at $0.5 \mathrm{~ms}$ ASOI; $p_{a m b}=0.1 \mathrm{MPa}$.

Regardless of the injection pressure, the spray collapse for the flare flash-boiling case is not appropriately represented, even though the spray penetration was predicted by the liquid phase very well. The droplets are distributed over further distances from the spray axis compared to the Schlieren images (darker region of the spray cloud). When the vapour phase is taken into account (marked with red lines), the spray cloud obtained by the Schlieren imaging is broader and more similarities between the experiments and simulations can be seen. However, due to the low spatial resolution of the Schlieren images, it is not known whether droplets are coexisting in the vapour regions. Additional droplet measurements would be essential to verify it.

\section{Summary and Conclusions}

In this study, the effect of flash boiling on the structures of liquid propane sprays formed at different injection pressures was evaluated in terms of trends observed for subcooled conditions. The lowest considered injection pressure was strongly reduced compared to typical SIDI engine-relevant conditions. In order to limit the impact of changing viscosity and surface tension, the temperature of the injected liquid was kept constant.

The spray structures were evaluated qualitatively and quantitatively. The quantitative analysis was performed by means of spray-tip penetration and the spray angle. The spray-tip penetration was measured along the axis of the single plume in order to assess how the propagation of the single plume is affected by the other plumes, especially under conditions of strong spray collapse. For the lowest ambient pressure (the highest propane's saturation-to-ambient pressure ratio), this analysis was made to evaluate the effect of the injection pressure. For reference, the effect of injection pressure was also assessed in subcooled conditions. 
The results showed very different spray behaviour in subcooled and flash-boiling conditions. The flashing sprays were surrounded by vapour clouds visualised by a Schlieren set-up, and the vapour clouds became more visible for lower injection pressures, exceeding the liquid phase in the tip area. This was linked to a slower propagation of the droplets at lower injection pressures. In the case of strong flash boiling, the sprays collapsed, leading to a much stronger penetration and narrower spray angle, which could not be expected based on the trends observed for subcooled conditions.

As for the injection pressure, its influence on the spray-tip penetration and the spray angle was very similar for both conditions, subcooled and flash boiling, even though the sprays were very different, and the spray collapse in the strong flash-boiling regime was present. The variations in the spray-tip penetration in terms of changing pressure difference (between in-injector liquid and ambience) could be explained by the correlations presented earlier by other researchers for sprays formed by single round nozzles. The spray angle, in turn, was very weakly influenced by the injection pressure, regardless of the conditions.

As far as the numerical simulations are concerned, there was no universal model set-up to represent the flashing sprays properly. Moreover, the spray collapse was not represented very well, making the simulation set-up more suitable for less superheated sprays. The bubble number density was a critical parameter in CFD calculations. The base model underestimated the number of bubbles resulting in the lack of a spray collapse. It was required to set the correction factor individually for each flashing case. Additional droplet size measurements would be essential to overcome these issues.

The study led to a general conclusion that the influence of injection pressure on propane sprays under strong flash boiling is very similar to that in subcooled conditions, even though very different spray behaviours in the subcooled and flash-boiling conditions are observed.

Author Contributions: Conceptualisation, Ł.J.K., J.B. and J.P.; methodology, Ł.J.K., J.B. and C.J.; software, J.B.; validation, Ł.J.K. and J.B.; formal analysis, Ł.J.K. and J.B.; investigation, Ł.J.K. and J.B.; resources, J.P., H.X. and M.L.W.; data curation, Ł.J.K. and J.B.; writing—original draft preparation, Ł.J.K. and J.B.; writing—review and editing, Ł.J.K., J.B. and J.P.; visualisation, Ł.J.K. and J.B.; supervision, H.X. and M.L.W.; project administration, Ł.J.K. and M.L.W.; funding acquisition, Ł.J.K. and M.L.W. All authors have read and agreed to the published version of the manuscript.

Funding: The project leading to this application has received funding from the European Union's Horizon 2020 research and innovation programme under the Marie Skłodowska-Curie grant agreement No. 691232. The research was co-financed by the Polish Ministry of Science within the frame of science support funds for international co-funded projects in 2016-2019.

Institutional Review Board Statement: Not applicable.

Informed Consent Statement: Not applicable.

Acknowledgments: Numerical simulations were performed using AVL FIRE ${ }^{\mathrm{TM}}$ software under AVL University Partnership Program.

Conflicts of Interest: The authors declare no conflict of interest. The funders had no role in the design of the study; in the collection, analyses, or interpretation of data; in the writing of the manuscript, or in the decision to publish the results.

\section{References}

1. Campbell, M.; Wyszyński, Ł.P.; Stone, R. Combustion of LPG in a Spark-Ignition Engine. SAE Trans. 2004, 113, 628-637. [CrossRef]

2. Zigan, L.; Schmitz, I.; Flügel, A.; Wensing, M.; Leipertz, A. Structure of evaporating single- and multicomponent fuel sprays for 2nd generation gasoline direct injection. Fuel 2011, 90, 348-363. [CrossRef]

3. Vanderwege, B.A.; Hochgreb, S. The effect of fuel volatility on sprays from high-pressure swirl injectors. Symp. Combust. 1998, 27, 1865-1871. [CrossRef]

4. Lamanna, G.; Kamoun, H.; Weigand, B.; Steelant, J. Towards a unified treatment of fully flashing sprays. Int. J. Multiph. Flow 2014, 58, 168-184. [CrossRef]

5. Brown, R.; York, J.L. Sprays formed by flashing liquid jets. AIChE J. 1962, 8, 149-153. [CrossRef] 
6. Li, S.; Zhang, Y.; Qi, W. Quantitative study on the influence of bubble explosion on evaporation characteristics of flash boiling spray using UV-LAS technique. Exp. Therm. Fluid Sci. 2018, 98, 472-479. [CrossRef]

7. Araneo, L.; Coghe, A.; Brunello, G.; Dondé, R. Effects of Fuel Temperature and Ambient Pressure on a GDI Swirled Injector Spray. SAE Tech. Pap. 2000, 13. [CrossRef]

8. Zhang, G.; Xu, M.; Zhang, Y.; Hung, D.L.S. Characteristics of Flash Boiling Fuel Sprays from Three Types of Injector for Spark Ignition Direct Injection (SIDI) Engines. In Proceedings of the FISITA 2012 World Automotive Congress; Springer: Berlin/Heidelberg, Germany, 2013; pp. 443-454.

9. Araneo, L.; Donde', R. Flash boiling in a multihole G-DI injector-Effects of the fuel distillation curve. Fuel 2017, 191, 500-510. [CrossRef]

10. Wang, Z.; Wang, B.; Jiang, C.; Xu, H.; Badawy, T. Microscopic characterization of isooctane spray in the near field under flash boiling condition. Appl. Energy 2016, 180, 598-606. [CrossRef]

11. Weber, D.; Leick, P. Structure and Velocity Field of Individual Plumes of Flashing Gasoline Direct Injection Sprays. In 26th Annual Conference on Liquid Atomization and Spray Systems (ILASS); Spinger: Berlin/Heidelberg, Germany, 2014; pp. 8-10. [CrossRef]

12. Zeng, W.; Xu, M.; Zhang, G.; Zhang, Y.; Cleary, D.J. Atomization and vaporization for flash-boiling multi-hole sprays with alcohol fuels. Fuel 2012, 95, 287-297. [CrossRef]

13. Xu, M.; Zhang, Y.; Zeng, W.; Zhang, G.; Zhang, M. Flash Boiling: Easy and Better Way to Generate Ideal Sprays than the High Injection Pressure. SAE Int. J. Fuels Lubr. 2013, 6, 137-148. [CrossRef]

14. Yang, S.; Li, X.; Hung, D.L.S.; Xu, M. Characteristics and correlation of nozzle internal flow and jet breakup under flash boiling conditions. Int. J. Heat Mass Transf. 2018, 127, 959-969. [CrossRef]

15. Lacey, J.; Poursadegh, F.; Brear, M.; Gordon, R.; Petersen, P.; Lakey, C.; Butcher, B.; Ryan, S. Generalizing the behavior of flash-boiling, plume interaction and spray collapse for multi-hole, direct injection. Fuel 2017, 200, 345-356. [CrossRef]

16. Poursadegh, F.; Lacey, J.S.; Brear, M.; Gordon, R.; Petersen, P.; Lakey, C.; Butcher, B.; Ryan, S.; Kramer, U. On the phase and structural variability of directly injected propane at spark ignition engine conditions. Fuel 2018, 222, 294-306. [CrossRef]

17. Zhang, Z.; Li, Y.; Ma, X.; Ding, H.; Xu, H.; Wang, Z.; Shuai, S. Characteristics of trans-critical propane spray discharged from multi-hole GDI injector. Exp. Therm. Fluid Sci. 2018, 99, 446-457. [CrossRef]

18. Kim, T.; Kim, D.; Park, S. Numerical approach to analyze propane flash boiling spray using modified gas-jet model. Appl. Therm. Eng. 2019, 162, 114255. [CrossRef]

19. Vetrano, M.R.; Simonini, A.; Steelant, J.; Rambaud, P. Thermal characterization of a flashing jet by planar laser-induced fluorescence. Exp. Fluids 2013, 54, 1573. [CrossRef]

20. Gärtner, J.W.; Feng, Y.; Kronenburg, A.; Stein, O.T. Numerical Investigation of Spray Collapse in GDI with OpenFOAM. Fluids 2021, 6, 104. [CrossRef]

21. Guo, H.; Nocivelli, L.; Torelli, R. Numerical study on spray collapse process of ECN spray G injector under flash boiling conditions. Fuel 2021, 290, 119961. [CrossRef]

22. Lemmon, E.W.; Bell, I.H.; Huber, M.L.; McLinden, M.O. NIST Standard Reference Database 23: Reference Fluid Thermodynamic and Transport Properties-REFPROP, Version 9.0; National Institute of Standards and Technology: Gaithersburg, MD, USA, 2010. [CrossRef]

23. Guo, H.; Li, Y.; Xu, H.; Shuai, S.; Zhang, H. Interaction between under-expanded flashing jets: A numerical study. Int. J. Heat Mass Transf. 2019, 137, 990-1000. [CrossRef]

24. Zuo, B.; Gomes, A.M.; Rutland, C.J. Modelling superheated fuel sprays and vaporization. Int. J. Engine Res. 2000, 1, 321-336. [CrossRef]

25. Adachi, M.; McDonell, V.G.; Tanaka, D.; Senda, J.; Fujimoto, H. Characterization of Fuel Vapor Concentration inside a Flash Boiling Spray. SAE Tech. Pap. 1997, 9. [CrossRef]

26. Abramzon, B.; Sirignano, W. Droplet vaporization model for spray combustion calculations. Int. J. Heat Mass Transf. 1988, 32, 1605-1618. [CrossRef]

27. Senda, J.; Nishikori, T.; Hojyo, Y.; Tsukamoto, T.; Fujimoto, H. Modelling of Atomization and Vaporization Process in Flash Boiling Spray. 2nd Report, Model Analysis on Atomization and Vaporization Process. Trans. Jpn. Soc. Mech. Eng. Ser. B 1994, 60, 3556-3562. [CrossRef]

28. Mikic, B.B.; Rohsenow, W.M.; Griffith, P. On bubble growth rates. Int. J. Heat Mass Transf. 1970, 13, 657-666. [CrossRef]

29. Hanjalić, K.; Popovac, M.; Hadžiabdić, M. A robust near-wall elliptic-relaxation eddy-viscosity turbulence model for CFD. Int. J. Heat Fluid Flow 2004, 25, 1047-1051. [CrossRef]

30. Post, S.L.; Abraham, J. Modeling the outcome of drop-drop collisions in Diesel sprays. Int. J. Multiph. Flow 2002, 28, 997-1019. [CrossRef]

31. Price, C.; Hamzehloo, A.; Aleiferis, P.; Richardson, D. Numerical modelling of fuel spray formation and collapse from multi-hole injectors under $\mathrm{fl}$ ash-boiling conditions. Fuel 2018, 221, 518-541. [CrossRef]

32. Wakuri, Y.; Fujii, M.; Amitani, T.; Tsuneya, R. Studies on the Penetration of Fuel Spray in a Diesel Engine. Bull. JSME 1960, 3, 123-130. [CrossRef]

33. Dent, J.C. A Basis for the Comparison of Various Experimental Methods for Studying Spray Penetration. SAE Tech. Pap. 1971, 1, 710571. [CrossRef]

34. Hiroyasu, H.; Arai, M. Structures of Fuel Sprays in Diesel Engines. SAE Tech. Pap. 1990, 99, 1050-1061. 
35. Schihl, P.; Bryzik, W.; Atreya, A. Analysis of Current Spray Penetration Models and Proposal of a Phenomenological Cone Penetration Model. SAE Tech. Pap. 1996, 12.

36. Arrègle, J.; Pastor, J.V.; Ruiz, S. The Influence of Injection Parameters on Diesel Spray Characteristics. SAE Tech. Pap. 1999, 10.

37. Pielecha, I. Modeling of gasoline fuel spray penetration in SIDI engines. Int. J. Automot. Technol. 2014, 15, 47-55. [CrossRef]

38. Reitz, R.D.; Bracco, F.B. On the Dependence of Spray Angle and Other Spray Parameters on Nozzle Design and Operating Conditions. SAE Tech. Pap. 1979, 24.

39. Siebers, D.L. Scaling Liquid-Phase Fuel Penetration in Diesel Sprays Based on Mixing-Limited Vaporization. SAE Trans. 1999, 108, 703-728. [CrossRef] 